\title{
O ATENDIMENTO PEDAGÓGICO ESPECIALIZADO E O ENSINO DE FÍSICA: UMA INVESTIGAC̄̃̃O ACERCA DO PROCESSO DE ENSINO E APRENDIZAGEM DE UMA ALUNA CEGA
}

\author{
MARCELA RIBEIRO DA SILVA - (https://orcid.org/0000-0002-9780-6232) \\ Universidade Estadual Paulista, Bauru, SP, Brasil \\ EDER PIRES DE CAMARGO - (https://orcid.org/0000-0003-2577-9885) “* \\ Universidade Estadual Paulista, Bauru, SP, Brasil
}

RESUMO: $\mathrm{O}$ artigo aborda o processo de ensino e aprendizagem de Física de uma aluna cega matriculada no Ensino Médio e que frequentava as salas de aula regular e de recursos. Buscou-se compreender como têm se configurado as práticas pedagógicas adotadas pelas professoras de Física e da sala de recursos, a articulação entre essas profissionais e algumas das dificuldades encontradas por elas e pela aluna nesse processo. Foram realizadas observações e entrevistas semiestruturadas. Os dados foram analisados à luz da Análise de Discurso de linha francesa. Os resultados indicam a ausência de parcerias entre as referidas professoras e um deslocamento da aprendizagem dos conteúdos de Física, que deveria se dar na sala de aula regular, para a sala de recursos.

Palavras-chave: Ensino de Física; Deficiência visual; Inclusão.

\section{EL ATENDIMIENTO PEDAGÓGICO ESPECIALIZADO Y LA ENSEÑANZA DE LA FÍSICA: UNA INVESTIGACIÓN ACERCA DEL PROCESO DE ENSEÑANZA Y APRENDIZAJE DE UNA ALUMNA CIEGA}

RESUMEN: El artículo aborda el proceso de enseñanza y aprendizaje de Física de una alumna ciega matriculada en la Escuela Secundaria que frecuentaba clases regulares y de recursos. Se ha buscado comprender cómo se tienen configurado las prácticas pedagógicas adoptadas por las profesoras de Física y del aula de recursos, la articulación entre esas profesionales y algunas de las dificultades encontradas por ellas y por la alumna en este proceso. Han sido realizadas observaciones y entrevistas semiestructuradas. Los datos han sido analizados bajo la luz del Análisis del Discurso de línea francesa. Los resultados indican la ausencia de colaboración entre las referidas profesoras y un desplazamiento del aprendizaje de los contenidos de la Física, que debería ocurrir en la clase regular, para el aula de recursos.

Palabras clave: Enseñanza de la Física; Discapacidad visual; Inclusión.

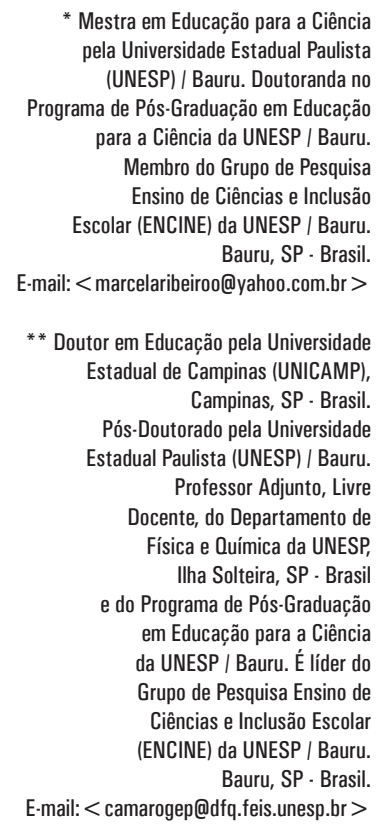

* Mestra em Educação para a Ciência pela Universidade Estadual Paulista (UNESP) / Bauru. Doutoranda no Programa de Pós-Graduação em Educação para a Ciência da UNESP / Bauru. Membro do Grupo de Pesquisa Ensino de Ciências e Inclusão Escolar (ENCINE) da UNESP / Bauru. Bauru, SP - Brasil.

E-mail:<marcelaribeiroo@yahoo.com.br >

** Doutor em Educação pela Universidade Estadual de Campinas (UNICAMP), Campinas, SP - Brasil. Pós-Doutorado pela Universidade Estadual Paulista (UNESP) / Bauru. Professor Adjunto, Livre Docente, do Departamento de Física e Química da UNESP, Illha Solteira, SP - Brasil e do Programa de Pós-Graduação em Educação para a Ciência da UNESP / Bauru. É líder do Grupo de Pesquisa Ensino de Ciências e Inclusão Escolar (ENCINE) da UNESP / Bauru. Bauru, SP - Brasil. E-mail:<camarogep@dfq.feis.unesp.br > 
SPECIALIZED PEDAGOGICAL SERVICE AND TEACHING PHYSICS: AN INVESTIGATION ABOUT THE TEACHING AND LEARNING PROCESS OF A BLIND STUDENT

ABSTRACT: This article discusses the teaching and learning Physics process of a blind student enrolled in High School that attended both regular classroom and resource room. It was sought to understand how the pedagogical practices adopted by the Physics teacher and by the resource room's teacher, the articulation between these professionals and some of the difficulties encountered by them and the student in this process are characterized. Observations and semi-structured interviews were conducted. The data was analyzed under the light of discourse analysis's French method. The results indicate the absence of partnership between the referred teachers and a displacement of learning Physics content, that should happen in regular classroom, to the resource room.

Keywords: Physics teaching; Visual impairment; Inclusion. 


\section{INTRODUÇÃO}

A produção acadêmica sobre o ensino de Física para alunos com deficiência visual (cegos ou com baixa visão) tem enfoque na elaboração de materiais didáticos / recursos/metodologias acessíveis a esses alunos. Camargo (2005), Tato e BarbosaLima (2007) e Dickman et al. (2014) elaboraram, respectivamente, um conjunto de atividades para o ensino do conceito de aceleração a alunos com deficiência visual, um material de equacionamento tátil para a resolução de problemas físicos e um conjunto de símbolos táteis para representar elementos usados em diagramas de mecânica com o objetivo de representar imagens de situações de Física presentes em livros didáticos. Outro tema abordado foram as concepções alternativas que sujeitos cegos têm sobre conceitos físicos (CAMARGO; SCALVI; BRAGA, 2000).

A compreensão sobre quais contextos comunicacionais dificultam e favorecem a participação de alunos com deficiência visual em aulas de Física também foi investigada (CAMARGO, 2010;CAMARGO; NARDI; VERASZTO,2008). No âmbito da formação inicial de professores de Física, pode-se citar o estudo acerca das representações sociais de licenciandos sobre a inclusão de alunos com deficiência visual (BARBOSA-LIMA; MACHADO, 2011) e o trabalho desenvolvido junto a futuros professores que, após participarem de discussões acerca do ensino de Física a alunos com a referida deficiência, elaboraram e aplicaram módulos de ensino no referido contexto (CAMARGO; NARDI, 2006).

Investigações sobre o estado do conhecimento no ensino de Física para alunos com deficiência visual (AZEVEDO; SCHRAMM; SOUZA, 2015; SILVA; CAMARGO, 2016) indicaram um crescimento no número de publicações nos últimos anos, apontando resultados importantes. Notou-se a ausência de estudos que tratam da relação entre o ensino de Física na sala de aula regular e o Atendimento Educacional Especializado (AEE) destinado aos estudantes com deficiência visual.

Ratifica a necessidade de estudos que abordem a referida relação, o fato de que, no Brasil, o apoio ao processo de escolarização dos alunos público-alvo da Educação Especial ${ }^{1}$ (PAEE) matriculados nas escolas regulares está previsto sob a forma do AEE. Esse atendimento está presente em todas as etapas e modalidades da educação básica e se constitui como oferta obrigatória dos sistemas de ensino (BRASIL, 2009).

O AEE não deve ser um atendimento substitutivo ou de reforço escolar ao ensino na sala de aula regular, mas complementar à formação dos alunos com alguma deficiência ou transtornos globais do desenvolvimento e suplementar à formação daqueles com altas habilidades ou superdotação (BRASIL, 2011).

No estado de São Paulo, o apoio à escolarização dos alunos PAEE é denominado Atendimento Pedagógico Especializado (APE). Consonante com a legislação nacional, ele é ofertado no contraturno, preferencialmente em salas de recursos ${ }^{2}$ e deve ser realizado de modo que as turmas sejam constituídas por "[...] alunos de uma única área de deficiência, ou de transtornos globais do desenvolvimento, ou de altas habilidades ou superdotação" (SÃO PAULO, 2014, p. 2).

O APE deve ser realizado por um professor especializado que tenha formação na área da necessidade educacional especial. A esse professor cabe, entre outras responsabilidades, “[...] oferecer apoio técnico-pedagógico ao 
professor da classe/aulas do ensino regular, indicando os recursos pedagógicos e de acessibilidade, bem como estratégias metodológicas; [...] participar de ações de formação continuada; [...]” (SÃO PAULO, 2014, p.3).

Depreende-se que deve existir uma articulação entre os professores da sala de recursos e da sala regular, de modo que uma das atribuições do primeiro é promover tal articulação. Ou seja, o APE deve ser realizado em interface com os professores do ensino regular, promovendo os apoios necessários à participação nas atividades escolares e aprendizagem dos estudantes PAEE.

Frente ao exposto, este artigo apresenta e discute resultados de um estudo cujo objetivo foi investigar como ocorria o processo de ensino e aprendizagem de Física de uma aluna cega congênita matriculada no $2^{\circ}$ ano do Ensino Médio em uma escola da rede pública estadual paulista de ensino, a partir de: entrevistas semiestruturadas com a referida aluna, sua professora de Física e a professora responsável pelo APE na sala de recursos, observações das aulas de Física e do APE realizado junto à aluna no contraturno.

O enfoque dessa investigação recaiu sobre: as práticas pedagógicas adotadas pelas professoras de Física e da sala de recursos; a articulação entre essas profissionais; algumas das dificuldades que essas profissionais e a aluna encontravam nas atividades desenvolvidas na interface APE- ensino de Física.

\subsection{SUJEITOCOM DEFICIÊNCIA VISUALESEU PROCESSO DEENSINOEAPRENDIZAGEM: UM OLHAR A PARTIR DA TEORIA DE VIGOTSKI}

Para Vigotski ${ }^{3}$, as interações do sujeito com o meio social em que está inserido são indispensáveis ao desenvolvimento de suas funções psíquicas superiores como, por exemplo, o pensamento lógico, a memória consciente e a capacidade de planejamento (PRESTES, 2010). Tal desenvolvimento é sempre mediado por signos e por outros indivíduos do grupo sociocultural, o qual atribui significado à realidade, se apropriando do comportamento e da cultura. Para tanto, todas as funções no desenvolvimento da criança aparecem duas vezes: primeiro no nível social (interpsicológico), e, posteriormente, no nível individual (intrapsicológico) (VYGOTSKY, 1991).

Nessa perspectiva teórica, a aprendizagem e o desenvolvimento cognitivo se inter-relacionam, de modo que esse é promovido pelo processo de ensinar e o esforço de aprender. Ou seja, as estruturas cognitivas necessárias à compreensão de um determinado conceito só são criadas/desenvolvidas na medida em que esse conceito é aprendido (GASPAR, 2007).

A aprendizagem decorre da interação social por meio da imitação, a qual não se trata de um processo meramente mecânico (VIGOTSKI, 2001). Para que a imitação ocorra se faz necessário ter alguma possibilidade de que o aprendiz possa passar a fazer com autonomia aquilo que ele faz com o auxílio de um parceiro mais capaz. Numa interação social, o parceiro mais capaz é aquele que é mais experiente, ou seja, que sabe fazer determinada tarefa ou que tem o domínio, por exemplo, de determinado conteúdo. Portanto, não há aprendizagem sem interação social, de modo que esta última só existe se houver, entre aqueles que participam dela, um parceiro mais capaz (GASPAR, 2007). 
No que concerne ao sujeito com deficiência, Vigotski enfatizou que o funcionamento psíquico deste obedece às mesmas leis que o de pessoas sem deficiência, todavia com uma organização distinta (VYGOTSKI, 1997). Uma ideia central na sua teoria sobre o sujeito com deficiência diz respeito à compensação social. $\mathrm{Na}$ falta da visão ocorre uma reorganização no aparato psíquico do sujeito, de modo a compensar a ausência desse sentido. Contudo, não se trata de uma compensação biológica de um dos sentidos, como o tato e/ou a audição, mas do desenvolvimento de tendências à super compensação, as quais estão orientadas à superação do conflito social e, consequentemente, à conquista de uma posição na vida social. Ou seja, do contato do cego com o ambiente externo decorre um conflito causado pela falta de correspondência entre o órgão deficiente e as tarefas definidas socialmente, ocorrendo, portanto, uma luta - que pode resultar em diversos níveis de fracasso ou sucesso - desse sujeito para superar a ausência da visão e se estabelecer socialmente (VYGOTSKI 1997).

Em síntese, a compensação social refere-se a uma reação do sujeito diante da deficiência - igualmente considerada uma construção social - de modo que, para o cego, o processo de compensação social pode ocorrer a partir da linguagem, pela experiência social e pelas relações sociais que ele estabelece (LIRA; SCHLINDWEIN, 2008).

Tomando o exemplo da cor branca, um cego de nascimento poderá se apropriar do seu significado de ordem social. Por meio de suas relações sociais, ele poderá associá-la à paz. Já o entendimento dessa cor em razão de sua representação mental visual não é possível a essa pessoa, pois há uma relação inseparável entre esse significado e a percepção visual (CAMARGO, 2012). Disso, pode-se concluir que os sentidos remanescentes (tato, olfato, audição e paladar) nunca ensinarão o cego a ver.

Ademais, a pessoa cega não sente sua cegueira diretamente, mas sim as consequências sociais de sua deficiência orgânica, as quais podem resultar em limitações, pois “ "[...] todos os nossos instrumentos, toda a técnica, todos os signos e símbolos são calculados para um tipo normal de pessoa" (VIGOTSKI, 2011, p. 867). As necessidades (educacionais) especiais "[...] não são propriedades ou exigências dos seres humanos, nem nascem com eles, mas se originam de um processo de produção material e social" (LIRA; SCHLINDWEIN, 2008, p.173). Portanto, a capacidade/dificuldade de um aluno cego em aprender Física não é intrínseca a este, mas decorre do fato de que o conhecimento científico, enquanto construção social, é comunicado/representado de forma inacessível a este sujeito, ou seja, por vias predominantemente visuais.

Assim, a interação social estabelecida no contexto escolar com vistas à aprendizagem de Física por um aluno cego deve ser mediada por materiais e estratégias acessíveis também aos sentidos do tato, da audição, do olfato e do paladar, sentidos esses compartilháveis entre alunos com e sem deficiência visual.

\section{METODOLOGIA}

A investigação caracterizou-se como um estudo de caso. O caso deve ter uma particularidade que mereça ser investigada por meio de um estudo que envolva uma multiplicidade de aspectos que o caracterizam (ANDRÉ, 2013). Foi 
realizado em duas escolas da rede pública de ensino do estado de São Paulo, as quais são identificadas como Escola A e Escola P e estavam localizadas em uma cidade do interior do referido estado. A primeira escola contemplava o Ensino Fundamental e Médio, e a segunda o Ensino Fundamental e uma sala de recursos destinada ao APE a alunos com deficiência visual.

Os participantes foram: a professora da sala de recursos da Escola P, que atuava nesta função desde 1992 e tinha formação em Filosofia e Pedagogia com habilitação em deficiência visual; a professora de Física da Escola A, que atuava na rede pública de ensino do estado de São Paulo desde 1988 e era formada em Fisioterapia, Ciências e Matemática, e Licenciatura em Física, tendo concluído este último curso em 1996, e; uma aluna cega congênita de 16 anos de idade, que possuía percepção de luminosidade, de vultos e de algumas cores. Ela frequentava, no período matutino, o $2^{\circ}$ ano do Ensino Médio na Escola A e, no contraturno, a sala de recursos na Escola P. Sua frequência na sala de recursos era de dois dias por semana, num período de aproximadamente 1 hora e 40 minutos por dia. A aluna e suas professoras de Física e da sala de recursos são identificadas, respectivamente, como: A, F e S.

O processo de constituição dos dados ocorreu entre os meses de março e junho de 2015. Deu-se por meio de entrevistas individuais semiestruturadas (APÊNDICE A) realizadas com todas as participantes e observações das aulas de Física da aluna A na sala de aula regular e do APE realizado junto a ela na sala de recursos. As observações tiveram como foco as práticas pedagógicas e a interação entre as professoras $\mathrm{F}$ e $\mathrm{S}$, a interação entre a aluna e essas professoras e entre a aluna e os colegas de classe.

\section{ANÁLISE DE DISCURSO: UM APORTE TEÓRICO-METODOLÓGICO PARA A ANÁLISE DOS DADOS}

O corpus dos dados foi constituído pelas transcrições das entrevistas e por diários de campo (registros escritos) referentes às observações.

O enfoque da análise dos dados recaiu sobre as transcrições das entrevistas. Os diários de campo, que foram tomados como um aporte complementar, possibilitaram traçar um panorama dos participantes (buscando a compreensão sobre quem são os sujeitos que falam e de onde falam), do contexto imediato em que ocorria o processo de escolarização da aluna, bem como a emergência de algumas das questões que compuseram as entrevistas semiestruturadas.

A análise dos dados pautou-se no referencial teórico da Análise de Discurso de linha francesa (AD), fundado por Michel Pêcheux no final da década de 60 do século passado e que tem Eni Orlandi como principal precursora no Brasil.

Em síntese, a perspectiva teórica da AD:

- Trabalha a relação língua-discurso-ideologia, sendo que a materialidade da ideologia é o discurso, cuja materialidade específica é a língua, complementando-se com "[...] o fato de que, como diz M. Pêcheux (1975), não há discurso sem sujeito e não há sujeito sem ideologia: o indivíduo é interpelado em sujeito pela ideologia [...]" (ORLANDI, 2002, p.17);

- Entende o discurso como efeitos de sentido entre locutores (PÊCHEUX, 1975). Não trata apenas da transmissão de informações 
e os dizeres não são transparentes, isto porque no funcionamento da linguagem, que coloca em relação sujeitos e sentidos afetados pela língua e pela história, há um complexo processo de constituição de tais sujeitos e produção de sentidos;

- $\quad$ O discurso é balizado por condições de produção. Elas podem ser em sentido estrito ou amplo. Estas se referem ao contexto imediato da enunciação e aquelas ao contexto sócio-histórico, ideológico. As condições de produção funcionam de acordo com os seguintes fatores: relação de sentidos, antecipação e relação de forças. O primeiro fator implica que todo discurso é parte de um processo discursivo mais amplo. O segundo fator ocorre quando o sujeito do discurso, ao se colocar no lugar do seu interlocutor, antecipa-se quanto ao sentido que seus dizeres produzem, de modo que dirá ou não aquilo que imagina que seu locutor queira ouvir. A relação de forças trata do lugar a partir do qual fala o sujeito, ou seja, se, por exemplo, o sujeito que fala, fala no lugar de um professor, suas palavras significam de modo distinto do que se falasse no lugar de um aluno;

- O silêncio pode instaurar sentidos. Há silêncios que indicam que o sentido pode ser outro e há palavras que silenciam outras palavras (ORLANDI, 2002).

$\mathrm{Na}$ análise dos dados buscou-se compreender aquilo que foi dito e nãodito nos discursos dos sujeitos, bem como a que sentidos se filiam e com quais outros dizeres se relacionam tais discursos.

\section{RESULTADOS E DISCUSSÃO}

Apresentam-se os resultados em duas partes. A primeira aborda a articulação entre as professoras de Física e da sala de recursos e a segunda trata das práticas pedagógicas que eram adotadas por essas profissionais, bem como de algumas das dificuldades que elas encontravam no atendimento às necessidades educacionais da aluna, e seus desencadeamentos sobre o APE enquanto atividade complementar e/ ou de reforço escolar ao ensino de Física realizado na sala de aula regular.

\subsection{Articulação entre as professoras de Física e da sala de recursos}

Sobre as parcerias entre as professoras F e S destacam-se as unidades de análise:

$[\ldots]^{4}$ Então e a sala de recursos também tem essa questão de você estar orientando o professor da classe comum, né, de estar "Oh, você pode fazer isso daqui". [...] Você vai passar um gráfico, vamos mudar esse gráfico vamos de uma vamos colocar por extenso, né, uma coisa, né, mudar isso daí $\left[\ldots . . .\left[\mathrm{S}_{1}\right]^{5}\right.$

A gente vai também nos $\mathrm{ATPC}^{6}$ das escolas, né. Que nem, no da A eu já fui uma vez, já semana que vem nós vamos de novo. Então, assim, orientando o professor "Não, você pode fazer desse jeito", "É melhor fazer desse" [...]. [ $\left.\mathrm{S}_{2}\right]$ 
Essas unidades de análise filiam-se ao discurso presente na Resolução SE nº 61 (SÃO PAULO, 2014), pois remetem à articulação entre o professor da sala de aula regular e o da sala de recursos, sendo função do segundo orientar o primeiro. Entretanto, essa articulação tem se caracterizado pelo distanciamento entre os referidos profissionais, como está dito nas unidades de análise que seguem:

Oh, ela conversou assim de uma forma geral na reunião... assim... pessoalmente, só eu e ela, falando sobre o aprendizado, Física... nunca conversei. $\left[\mathrm{F}_{1}-\right.$ ao se referir à presença da professora S nas Aulas de Trabalho Pedagógico Coletivo (ATPC)]

Não, de Física. É, porque o que nós tivemos, mas era supletivo, era diferente. Então, às vezes assim eu tinha dúvida pra passar para o aluno eu ia lá conversar, né. Mas assim de não, a gente não teve nem um. Tanto é que está tendo toda essa parte que nem agora da Matemática, da Física e da Química, que está pegando mais, que a gente vai estar conversando, até, o pessoal da diretoria vai lá. [...] então não tem, não tem, não teve nada assim de [...] E eu falo assim e o material, né, que até agora não chegaram as apostilas, você não tem um livro, e aí, que nem, quando é outra escola fica mais complicado, né, você não tem um contato direto, né. Porque quando você está ali todo dia, então eu chego aí, então vai passar um negócio "Tô em dúvida”, aí o professor, eu, né, corro atrás do professor $[\ldots] .\left[\mathrm{S}_{3}\right]$

Ainda que algumas das ATPC realizadas na Escola A tenham se configurado como um espaço de orientação aos professores da sala de aula regular, não houve parcerias entre F e S naquilo que concerne especificamente à disciplina de Física. Ademais, as supramencionadas orientações ocorreram de forma esporádica, de modo que a professora $\mathrm{S}$ se deslocou até a Escola A uma vez durante o período de constituição dos dados.

A sala de recursos estava localizada em uma escola que contemplava apenas o Ensino Fundamental e que era, portanto, distinta daquela escola em que A estava matriculada no Ensino Médio. Além disso, a professora da sala de recursos atendia um total de dezessete estudantes com deficiência visual. Desses, apenas quatro frequentavam a sala regular na mesma escola em que a sala de recursos estava localizada. Isso significa que a professora S, além de atender esses alunos na sala de recursos, tinha que se deslocar para diversas escolas a fim de dar orientação aos professores da sala de aula regular, implicando na impossibilidade de um contato mais próximo e frequente com as referidas instituições de ensino regulares. O exposto é previsto e legitimado pela Resolução SE nº 61 (SÃO PAULO, 2014).

Lippe (2010), em seu estudo, verificou que dos professores da sala regular e de recursos que trabalhavam numa mesma escola, poucos estabeleceram parcerias com vistas a buscar na sala de recursos um apoio à escolarização do aluno com deficiência visual, permanecendo a ideia de que nesse ambiente deve ocorrer o reforço escolar.

\subsection{APE: 0 complementar e o substitutivo ao ensino de Física}

O APE realizado na sala de recursos configurava-se ora como complementar, ora como reforço escolar ao ensino da sala de aula regular, sendo que este último 
tipo de configuração marcou sobremaneira os discursos dos sujeitos.

Com relação às atividades complementares, destaca-se a unidade de análise:

[...] tem muita gente que se confunde e fala "Ai, tem problema de alfabetização". Eu vejo assim: quando é intelectual [aluno com deficiência intelectual] eles mandam, ah, o aluno dá trabalho vai para a sala de recursos, né. A sala de recursos deficiente visual é o quê? Está falando: recursos. Nós temos todo o aparato. Então até a questão de material em braille, de livros, de computador, né, internet, agora que a gente tem, impressora tal. O que a função da sala de recursos é auxiliar o aluno com que ele consiga acompanhar a sala comum. [...] então a gente vai orientar a questão do braille, a questão de ampliar material, a questão de adaptar o material. [...] Mas é então, para fazer um trabalho, para você auxiliar como que você vai fazer o trabalho, aí você vai ter que estar transcrevendo. Então e a sala de recursos também tem essa questão de você estar orientando o professor da classe comum. [...] Você vai passar um gráfico, vamos mudar esse gráfico vamos de uma vamos colocar por extenso [...] então a função de ensinar o braille, de utilizar a internet, de usar o a aprender a usar o soroban, da locomoção, né [...]. [ $\mathrm{S}_{4}$ - ao se referir ao seu trabalho na sala de recursos, bem como sobre a função desse ambiente escolar no processo de ensino e aprendizagem de alunos com deficiência visual]

Frente à organização psicofisiológica do sujeito "anormal", a educação tem um papel fundamental no seu processo de compensação social. Ela o auxilia por meio da elaboração de um sistema de técnicas artificiais, culturais e de um sistema de signos adequados às suas peculiaridades. Pelo uso do sistema braille e do leitor de tela do computador, a aluna cega lê, assim como a professora vidente lê. Essa função cultural é garantida por um aparato psicofisiológico diverso(VIGOTSKI, 2011).

O APE teve um importante papel no processo de compensação social (VYGOTSKI, 1997) da aluna por meio do desenvolvimento de atividades complementares ao ensino na sala de aula regular, tais como: ensino da escrita braille de equações, unidades de medida e grandezas físicas; uso do computador com programa de interface auditiva (DOSVOX); ensino do soroban; ensino do reglete; leitura oral, pela professora S, de enunciados de exercícios/textos/avaliações em formato inacessível à aluna; realização de transcrição de materiais como, por exemplo, enunciados e resoluções de avaliações escritas e trabalhos, originalmente escritos em braille, para a escrita em tinta (transcrição braille-tinta), bem como seu inverso.

A transcrição tinta-braille/braille-tinta foi a principal atividade complementar ao ensino de Física. As unidades de análise sequentes enfocam tal atividade:

[...] Que que a gente faz é mandar a prova para a professora da sala de recursos, né [...] para a professora passar para o braille e depois ela traz as transcrições... O caminho tem sido isso, né. Ela tem utilizado o braille para escrever o que eu falo na sala, para responder as questões e depois a professora da sala manda a transcrição [...]. [ $\left.\mathrm{F}_{2}\right]$

Ah, já, eu acho que seria mais difícil... porque como que iria transcrever, né?... não iria ter como. $\left[\mathrm{A}_{1}-\right.$ ao ser questionada sobre como ela imaginava que seria aprender os conteúdos das disciplinas se não frequentasse a sala de recursos] 
A professora S, por meio das transcrições em braille e alto relevo, assumia um duplo papel, extremamente relevante, no processo de ensino e aprendizagem de Física da aluna. Ou seja, o trabalho com identidade e diferença entre a discente cega e sua docente de Física (CAMARGO, 2016a).

No trabalho com a diferença, a professora da sala de recursos viabilizava o acesso da estudante cega aos modelos matemáticos, tabelas e à escrita da língua portuguesa por meio do código braille, uma vez que a docente de Física desconhecia o referido código.

No trabalho com a identidade, a profissional da sala de recursos, por meio de representações em alto relevo, viabilizava o acesso da estudante cega aos gráficos, diagramas, figuras, etc., ou seja, às representações táteis comuns entre a discente cega e tateante e a docente vidente e igualmente tateante.

As ações descritas possibilitaram o processo de avaliação da aluna por meio de instrumentos tais como provas e trabalhos escritos.

Por meio do processo de transcrição foi possível a comunicação escrita entre a professora de Física vidente e a aluna cega. Investigações alertam para problemas recorrentes nas transcrições tinta-braille realizadas por meio do software Braille Fácil (TATO;BARBOSA-LIMA, 2009)e por professores do APE (SILVA; CAMARGO, 2017): a não consideração das peculiaridades do sistema braille no momento da transcrição gera inconsistências entre a avaliação escrita em tinta elaborada pelo professor de Física e aquela transcrita para o braille entregue ao aluno cego.

A aprendizagem decorre da interação social pela imitação (VIGOTSKI, 2001). Portanto, as inconsistências observadas nessas transcrições podem refletir na escrita do aluno cego e acarretar-lhe resultados comprometedores. $\mathrm{O}$ aluno fará uma avaliação escrita e o professor de Física corrigirá outra (TATO; BARBOSA-LIMA, 2009). Acentua essa problemática o fato de que não há um documento normatizador da grafia braille na área da Física. S recorria ao Código Matemático Unificado para a Língua Portuguesa (CMU) (BRASIL, 2006) e muitas vezes ela "criava" uma representação própria que era ensinada à aluna, afastando-se de uma escrita padrão.

Para Vigotski, a deficiência visual enquanto deficiência orgânica não implica, necessariamente, em impossibilidade de aprendizagem, de modo que "[...] ao se proporcionar, ao cego, formas alternativas de acesso aos aspectos da cultura inacessíveis a ele devido à ausência de visão, o problema será contornado [...]" (LIRA; SCHLINDWEIN, 2008, p.181).

Uma das dificuldades de ensino e aprendizagem de Física de A era a seguinte: o livro didático e o Caderno do Aluno ${ }^{7}$ que foram disponibilizados a ela estavam em tinta. A esse respeito seguem as unidades de análise:

A apostila (Caderno do Aluno)... o livro... mas o livro não é em braille, é em tinta, né... então aí você... eu estudo com a minha amiga ou na minha casa ou aqui. E a apostila é em braille. $\left[\mathrm{A}_{2}\right.$ - sobre os materiais didáticos disponibilizados à A pela Escola $\left.\mathrm{A}\right]$

Ah não é muito bom, né, porque como a gente vai fazer? Eu ainda que dou meu jeito, que eu tenho meus amigos, minha professora... aí eles me ajudam. $\left[\mathrm{A}_{3}\right.$ - sobre o atraso na entrega do Caderno do Aluno] 
Então, assim, a gente pode dizer que aqui a sala de recursos aqui no estado de São Paulo, [nome da cidade onde foi realizada a pesquisa], ela tem, ela realmente funciona porque ela tem esses recursos. Mas por um lado, que nem, esse ano, o que aconteceu, não chegaram as apostilas em braille, que é o que o governo manda, o Caderno do Aluno, lá, esse ano não chegou por problemas técnicos e eu sei mais, né, do governo, e não veio. Então isso, quer dizer, já fica falho nesse ponto, né. Você não consegue acompanhar nesse igual os outros, né. $\left[S_{5}-\right.$ sobre materiais/recursos disponíveis no ambiente da sala de recursos]

Embora A afirme que o Caderno do Aluno seja disponibilizado em braille, houve um atraso na entrega desse material,situação consonante àquela encontrada na investigação de Lippe (2010). O Caderno do Aluno em braille referente ao primeiro semestre letivo foi entregue no final de junho, ou seja, no final do referido semestre.

Considerando: a pouca disponibilidade de livros didáticos em braille e do Caderno do Aluno; que os livros em braille existentes na sala de recursos eram, em sua maior parte, de literatura e alguns de Matemática e todos referentes ao Ensino Fundamental; que algumas das condições de produção, em sentido estrito, desses discursos concernem ao fato de que a professora $\mathrm{F}$, durante suas aulas, apoiava-se majoritariamente no Caderno do Aluno, dois não-ditos se colocam.

O primeiro não-dito diz respeito ao fato de que a aluna se encontrava em desvantagem em relação aos demais colegas, uma vez que sua autonomia nos estudos ficou prejudicada, pois ela sempre dependia da professora da sala de recursos, de seus colegas e de seus familiares para lerem oralmente os conteúdos do Caderno do Aluno, de modo que o acesso às informações referentes às atividades desse material didático e seu tempo de estudos ficavam limitados.

A falta de autonomia e independência nos estudos é uma dificuldade encontrada também pelos estudantes que têm acesso ao livro didático em braille. Quando o livro é transcrito, algumas figuras são suprimidas e no lugar delas lê-se "peça ajuda ao professor". O aluno depende de uma audiodescrição a ser realizada por outrem e que nem sempre é satisfatória. Por vezes, ela é realizada por pessoas que não têm conhecimento da linguagem específica da Física e que acabam utilizando analogias e termos desconhecidos para esses estudantes (DICKMAN et al., 2014).

O segundo não-dito refere-se a uma implicação no trabalho da professora da sala de recursos. Ficava a cargo dela tornar acessível (lendo oralmente, ampliando ou digitando em braille) o conteúdo desse material em tinta. Isso pode levar à sobrecarga das funções desempenhadas por essa profissional (LIPPE, 2010). Ademais, pode-se tomar como não-dito que o período e frequência semanal em que a aluna recebia o APE na sala de recursos eram insuficientes para atender às suas necessidades, pois eram realizadas atividades relacionadas a todas as disciplinas cursadas pela estudante.

As unidades de análise que seguem tratam das atividades realizadas durante o APE e que o configuravam como substitutivo/reforço escolar ao ensino de Física na sala de aula regular. Dentre essas atividades, destacaram-se: a realização de tarefas para a casa; quando A solicitava, à professora S, o esclarecimento de dúvidas/explicação sobre os conteúdos abordados nas aulas de Física.

E é um espaço onde tem um profissional para estar... intermediando aí, né, fazendo uma 
ponte entre o que ela vê aqui na escola e o aprendizado lá... $\left[\mathrm{F}_{3}\right.$ - resposta ao ser questionada sobre o que é a sala de recursos]

Aí, eu não sei... Isso eu ignoro [...] que atividades que ela faz lá... Boa pergunta, né! Quais são as atividades, além dela transcrever tudo que ela leva daqui e passar, fazer a transcrição, que outras... que outros recursos ela utiliza lá... Porque não deve ficar discutindo SÓ sobre as questões daqui da escola, né... Deve trabalhar algumas outras coisas, eu não sei [...]. [ $\mathrm{F}_{4}$ - resposta ao ser questionada sobre quais atividades são desenvolvidas na sala de recursos]

[...] ela tem que rever, né. Eu não sei como que acontece isso... Ela vai uma vez por semana na sala de recursos. E depois, o resto da semana, ela estuda? [...]. [ $\mathrm{F}_{5}-$ ao se referir à aluna $\left.\mathrm{A}\right]$

[...] Não sei o que ela [a aluna A] relata lá... a professora da sala de recursos também pode ser que numa disciplina ou outra ela também tenha dificuldade em entender, né. Não sei como é [...] A professora da sala de recursos, ela é multidisciplinar? Ou é por conta das estratégias que ela aplica e ela consegue transcorrer sobre todas as disciplinas? É uma professora só, não é? [ $\mathrm{F}_{6}$ - imaginário sobre a formação da professora da sala de recursos]

$\mathrm{O}$ discurso de F se vincula à ideia do APE como reforço escolar. Corrobora com o exposto o fato de que, ao longo do período de constituição dos dados dessa investigação, a professora F solicitou à primeira autora deste artigo que, durante as observações na sala de recursos, esclarecesse possíveis dúvidas de A a respeito dos conteúdos de Física que estavam sendo trabalhados na sala de aula regular.

No imaginário de F, a professora da sala de recursos é uma parceira mais capaz (VIGOTSKI, 2001) no ensino de conteúdos de Física, pois atribuiu a ocorrência de aprendizagem desses conteúdos no referido ambiente educacional. Ainda com relação às atividades de reforço escolar realizadas durante o APE:

[...] E aí não é sempre fazer TAREFA ou não é para fazer, que nem às vezes aí eu vou lá para fazer tarefa, não é. Que nem, você vê na $A$, ela vem com aquela atividade que não o professor, eu, não sou formada em Matemática, eu estou falando especificamente de ontem. Mas você vai o que, eu vou passar a pontuação que tem que como eu vou passar isso para ela, que o professor não consegue passar [...]. [S $\mathrm{S}_{6}$ - discurso sobre qual a função da sala de recursos no processo de ensino e aprendizagem de alunos com deficiência visual]

É, na Física é a mesma coisa também, você vê, ela fez, foi de Física que ela fez aquele exercício, não foi? De... Então, no começo do ano teve aquela aquela ela mandou uma uma tanto é que era uma tarefa que era de pesquisa, aí a mãe dela brigou, que era. Aí nós começamos a fazer e a gente não tinha internet ainda, eu coisei no celular. E mas eram coisas assim, coisas que dava pra fazer, mas se você mandar antes esse material, se você. Mas o que acontece, eu vejo aqui, que às vezes o professor ele não preparou antes, você entendeu? [...] Esse antes tem que ser bem antes, né, porque até você fazer essa ligação [...]. [S7]

Com relação à Física, vamos ver... Não, eu acho que é mais realmente a matéria específica, né, para estar auxiliando no entendimento mesmo da matéria, né. $\left[\mathrm{S}_{8}-\right.$ sobre que tipo de apoio, com relação à Física, a aluna solicitava na sala de recursos] 
[...] porque às vezes a professora, que nem, não sabe passar porque, ai, porque ela é, porque é muito, a coisa é muito visual, que nem, aquele exercício era muito visual, você tinha, né, porque tem,aí não sabe passar. Aí,que nem,o que que acontece, aí você tem uma maneira diferente, né, você vai fazer de uma maneira diferente para poder auxiliar, mas não que eu sei te explicar,né, ah eu sou especialista, eu não sou especialista na Matemática, na Química, na Física. Só que você faz o que: pede orientação, ai você passa e vai passar para ela. $\left[\mathrm{S}_{9}\right]$

A aluna também reconhecia a professora do APE como parceira mais capaz (VIGOTSKI 2001) no ensino de Física, pois solicitava a essa profissional auxílio na resolução de exercícios dessa disciplina. Mas S não se considerava como tal. O que de fato não faz parte de sua função didático-pedagógica. Ao dizer que $\mathrm{S}$ assume a posição de parceira mais capaz na mencionada interação social, não se está dizendo que ela tem conhecimentos específicos para isto, mas que ela pesquisava e buscava auxílio dos professores da própria escola onde estava localizada a sala de recursos.

A necessidade do envio do material com antecedência, explicitada por S na unidade de análise $S_{7}$, parece ser justificada tanto pelo fato de que essa profissional precisava estudar/pesquisar sobre o conteúdo do qual tratava a atividade, quanto com relação à seleção e adequação de materiais para que a aluna pudesse realizar as atividades propostas.

O perfil dos conhecimentos de Química, Física e Matemática da docente da sala de recursos influiu em sua atuação na formação da aluna. Isso ocorreu explicitamente em atividades de cunho complementar, tais como a leitura oral de símbolos representativos de unidades de medidas e grandezas físicas. A título de exemplo, foi observada, na sala de recursos, uma situação em que a professora $S$ teve grande dificuldade em comunicar à estudante os símbolos representativos dos elementos potássio $(\mathrm{K})$ e sódio $(\mathrm{Na})$, bem como a unidade de concentração, que é mol dividido por litro (mol/l). Foi necessário consultar um livro didático em tinta. Ao ler um de seus exercícios, $\mathrm{S}$ mencionou várias vezes que não sabia como se lia o que estava escrito. Isso dificultou a compreensão por parte da aluna.

A formação de professores responsáveis pelo APE não possibilita a eles a bagagem necessária para contribuírem com o trabalho pedagógico desenvolvido na sala de aula regular, pois "[...] construíram e focaram seu trabalho pedagógico nas dificuldades específicas do estudante por eles atendido, centralizando suas atividades na minimização dos efeitos específicos das várias deficiências" (MELO, 2013 , p. 56). Na sua formação, o pedagógico é secundarizado e a articulação entre o AEE e a sala comum não é o foco. Isso pode "[...] sinalizar que a proposta de inclusão em curso no país não pressupõe a apropriação do conhecimento escolar por parte dos alunos com deficiência” (MICHELS, 2011, p. 229).

Sobre o APE, enquanto atendimento de reforço escolar, tem-se que o papel da professora da sala de recursos no ensino de Física à aluna A é reforçado pelo fato de que F não adotou, durante o período de constituição de dados, nenhuma estratégia com vistas a incluir a aluna nas aulas de Física, exceto a leitura oral dos conteúdos que eram escritos por ela na lousa - com uso excessivo de uma linguagem de estrutura empírica audiovisual interdependente, que consiste na dependência mútua entre os códigos visual e auditivo comunicados, de modo que sua compreensão só pode se dar por meio do acesso simultâneo a tais códigos (CAMARGO, 2012). 
Pelo mecanismo de antecipação, e legitimando a ausência de estratégias com vistas a incluir a aluna nas aulas de Física, os discursos das professoras estiveram marcados pela ausência de capacitação docente e por suas condições de trabalho, tais como: salas de aula superlotadas, carga horária excessiva, etc... Quer dizer, as condições formativas e estruturais da escola, conforme está dito a seguir:

[...] Então eu também precisaria me capacitar, precisaria me formar, já que daqui para a frente isso daí vai ser uma rotina na sala de aula, ele tem que me capacitar para isso... Eu sozinha não vou conseguir, né... nós somos um grupo, uma equipe... e a gente precisava de

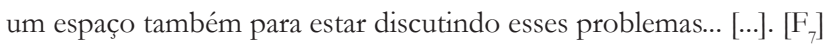

[...] Porque acontece assim, o que eles pedem, e esses professores têm razão, é que dão mais é e não sou eu, tem que ser um professor da área realmente, por exemplo, um assistente técnico-pedagógico, que é o ATP que tem lá na Diretoria, porque cada um tem: tem o de Química, tem o de Física, tem o de cada um. Esses estar orientando esses professores, porque eles têm, eles vão em São Paulo ter orientação para passar. [...] Só que eles não repassam isso para o professor, eles falam que o professor não pode ficar saindo da sala de aula para orientação. [...] Aí o que os professores reclamam: a sala é imensa, né, de alunos. Como que você vai conseguir atender, gente? Então, quer dizer, fica então fica inviável. [ $\left[\mathrm{S}_{10}\right]$

Esses dizeres perpassam por aquilo que Camargo (2012) chamou de "atribuição de responsabilidades", que concerne ao fato de que o professor assume que não é capaz de planejar atividades de ensino, justificando sua passividade na ausência de formação e de recursos materiais adequados para a promoção da inclusão na escola, terceirizando a outrem sua ação.

A necessidade de formação de professores para o trato com alunos PAEE é uma tônica nos discursos sobre a inclusão escolar, erigindo nos discursos de participantes de diversas investigações (BASSO, 2015; BARBOSA-LIMA; MACHADO, 2011; CAMARGO; NARDI; RUBO, 2014; LIPPE, 2010).

A Resolução CNE/CP 2 (BRASIL, 2015) contempla - aligeiradamente - a temática da inclusão e diversidade, de modo que os licenciados deverão estar aptos a:

[...] demonstrar consciência da diversidade, respeitando as diferenças de natureza ambientalecológica, étnico-racial, de gêneros, de faixas geracionais, de classes sociais, religiosas, de necessidades especiais, de diversidade sexual, entre outras [...] (BRASIL, op. cit. Art. 8, inciso VIII).

Não obstante, ao analisar a inserção da temática da educação inclusiva de estudantes PAEE em cursos de licenciatura em Ciências da Natureza (Física, Química e Biologia) das universidades públicas estaduais do estado de São Paulo, Basso (2015) concluiu que esses cursos não têm possibilitado formação inicial com vistas à atuação pedagógica junto ao referido público-alvo, fazendo-se

[...] necessário que a formação continuada possa proporcionar essa formação agregando à prática do professor de Ciências as teorias disponíveis até o momento, que possam auxiliar esse professor no tocante à educação [...] (BASSO, 2015, p.109). 
De encontro a essa necessidade, o estudo de Lippe (2010) relatou a falta de interesse e de condições dos professores em realizar cursos de formação continuada nessa temática. Por vezes, o horário e o local em que esses cursos são ofertados são de difícil acesso a esses profissionais.

\section{CONSIDERAC̣̃̃ES FINAIS}

A ocorrência da aprendizagem de Física por alunos com deficiência visual demanda o estabelecimento de uma interação social: na qual pelo menos um dos participantes seja o parceiro mais capaz (VIGOTSKI, 2001) nessa área; que favoreça o processo de compensação social (VYGOTSKI, 1997) garantindo um ensino comum e acessível a todos na sala regular e um apoio às especificidades desses estudantes.

Inscrevendo-se nos moldes da legislação atual e pelo viés da teoria de Vigotski, ao professor de Física caberia o papel de parceiro mais capaz no ensino dos conteúdos dessa disciplina por meio de atividades comuns a todos os alunos pelo uso, por exemplo, de maquetes multissensoriais, cuja elaboração deve ocorrer em conjunto com o professor do APE, o qual deve ser o parceiro mais capaz no ensino da linguagem escrita a ser utilizada por esse aluno na sala comum.

Conclui-se que o processo de ensino não favorecia, de modo incisivo, a compensação social para a ocorrência satisfatória da aprendizagem de Física pela estudante cega. Isso porque:

- A sala de aula regular se configurava como um ambiente no qual prevaleceu a ausência de estratégias e materiais didáticos acessíveis a todos os alunos;

- Ocorria um deslocamento do ensino de conteúdos específicos da Física, que deveria se dar na sala comum, para a sala de recursos, marcando o APE também por atividades de reforço escolar. Esse deslocamento implicava na atribuição da posição de parceiro mais capaz no ensino de Física à professora do APE que não era a parceira mais capaz com relação a esses conteúdos;

- O perfil dos conhecimentos de Física, Química e Matemática da professora do APE, a falta de domínio do CMU (BRASIL, 2006) por essa profissional e a ausência de um documento que padronize a escrita braille na área da Física comprometeram a sua atuação enquanto parceira mais capaz na realização de atividades complementares como a leitura oral dos conteúdos de Física, o ensino da grafia braille e a transcrição de materiais.

Conquanto a existência das problemáticas mencionadas, as atividades complementares citadas conferiram ao APE um papel fundamental ao processo de inclusão da aluna na sala comum. Por outro lado, a realização de atividades de reforço escolar reforçou a segregação.

Defende-se a necessidade de problematizar a inclusão de alunos com deficiência visual por meio de discussões, trabalhos e da aproximação dos (futuros) professores de todas as áreas com as distintas formas de diferenças (BARBOSALIMA; MACHADO, 2011). Uma vez que o processo de inclusão escolar desses estudantes implica na interação entre o APE e o ensino comum, é indispensável implementar ações com vistas a garantir: 
- A formação do professor de Física, de modo a abordar discussões e reflexões sobre a existência de apoios como o APE, as especificidades desse atendimento no processo de ensino e aprendizagem de alunos com deficiência visual, bem como sobre as funções desse professor na interface APE- ensino de Física. Esses aspectos são relevantes para o ensino dos alunos com e sem deficiência visual, pois o docente deve compreender que assim como existem conhecimentos e estratégias comunicacionais que não dependem da visão, há também conhecimentos e estratégias comunicacionais que podem ser relacionados ao ver, ouvir, tocar, etc. (CAMARGO, 2016a);

- A formação do professor especializado, proporcionando-lhe discussões e reflexões sobre a articulação entre o APE e o ensino comum e o domínio das representações em braille específicas das disciplinas de Química, Física e Matemática para garantir ao aluno cego a aprendizagem da grafia braille de acordo com as normativas de padronização;

- Ações que visem promover a articulação entre o trabalho dos professores de Física e da sala de recursos. Isso perpassa tanto pela capacitação desses profissionais, quanto pelas melhorias nas suas condições de trabalho e estruturais da escola. É fundamental que o professor que tenha um aluno com deficiência visual matriculado em sua sala de aula possua, em sua carga horária, tempo previsto para que, em conjunto com o professor do APE, possa planejar e se envolver em processos de elaboração de metodologias, experimentos e maquetes acessíveis a todos os alunos (CAMARGO, 2016b), como também discutir sobre o processo de transcrição de materiais.

Melo (2013) buscou promover ações colaborativas entre uma professora de Química e uma professora da Educação Especial de uma escola polo no atendimento a alunos com deficiência visual. O diálogo entre essas professoras se mostrou positivo e foram realizadas adequações em materiais didáticos que, posteriormente, foram utilizados durante as aulas na sala de aula regular.

Vilaronga e Mendes (2014) apontaram o ensino colaborativo/coensino como possibilidade para a articulação entre os professores da sala de aula regular e aqueles especializados. O coensino requer a redefinição do papel do professor especializado: o apoio é centrado na sala de aula regular, não se restringindo a serviços que envolvam a retirada dos alunos PAEE da sala comum. O coensino compõe a proposta de alguns países para a inclusão escolar desses estudantes, tendo sido apontada como promissora. No Brasil, esse modelo é pouco conhecido e vem sendo desenvolvido em casos pontuais, principalmente no âmbito do Ensino Fundamental. Se o coensino aproxima os professores da sala comum e do APE, uma questão lacunar se coloca: como se daria essa proposta no contexto do ensino de Física para alunos com deficiência visual? Que papéis assumiriam os professores envolvidos?

Por fim, ainda que não se negue que a inclusão escolar de alunos com deficiência visual seja comprometida tanto por aspectos estruturais da escola, quanto pelas condições de trabalho e de formação dos professores que têm em suas salas de aula alunos com tal deficiência, entende-se que é necessário transcender os limites do 
jogo imaginário de atribuição de responsabilidades, pois posicionar-se passivamente diante de tais aspectos "[...] é não buscar alternativas para superar as dificuldades oriundas do ensino para alunos com deficiência visual” (CAMARGO, 2012, p.34).

\section{AGRADECIMENTOS}

À Coordenação de Aperfeiçoamento de Pessoal de Nível Superior (CAPES) pelo apoio financeiro.

\section{REFERÊNCIAS}

ANDRÉ, M. E. D. A. O que é um estudo de caso qualitativo em educação? Revista da FAEEBA Educação e Contemporaneidade, v. 22, n. 40, p. 95-103, 2013.

AZEVEDO, S. S. M.; SCHRAMM, D. U. S.; SOUZA, M. O. O Ensino de Física e a Educação Inclusiva nas publicações: a educação do aluno com deficiência visual. In: Simpósio Nacional de Ensino de Física, XXI. Uberlândia, MG, jan. 2015. Atas... Uberlândia, 2015. Disponível em: http:// www.sbf1.sbfisica.org.br/eventos/snef/xxi/sys/resumos/T0055-1.pdf. Acesso em: 08 out. 2015.

BARBOSA-LIMA, M. C. A.; MACHADO, M. A. D. As representações sociais dos licenciandos de Física referentes à inclusão de deficientes visuais. Rev. Ensaio, v. 13, n. 3, p. 119-131, 2011.

BASSO, S. P. S. Cursos de licenciatura na área de ciências: a temática inclusão escolar de alunos com necessidades educacionais especiais. 2015. 131f. Tese (Doutorado em Educação para a Ciência) - UNESP, Bauru, 2015.

BRASIL. Ministério da Educação, Conselho Nacional de Educação, Conselho Pleno. Resolução CNE/CP2, de 01 de julho de 2015, Define as Diretrizes Curriculares Nacionais para a formação inicial em nível superior (cursos de licenciatura, cursos de formação pedagógica para graduados e cursos de segunda licenciatura) e para a formação continuada. Brasília: Diário Oficial da União, 02 de julho de 2015 .

BRASIL. Casa Civil. Decreto n. 7.611, de 17 de novembro de 2011. Brasília: Diário Oficial da União, 17 de nov., 2011. Disponível em: http://www.planalto.gov.br/ccivil_03/_ato2011-2014/2011/ decreto/d7611.htm.Acesso em: 08 mar. 2014.

BRASIL. Ministério da Educação, Conselho Nacional de Educação, Câmara de Educação Básica. Resolução CNE/CEB/n.4, que Institui Diretrizes Operacionais para o Atendimento Educacional Especializado na Educação Básica, modalidade Educação Especial.Diário Oficial da União, Brasília, 2 de out., 2009. Disponível em: http://www.planalto.gov.br/ccivil_03/_ato2007-2010/2008/ Decreto/D6571.htm. Acesso em: 03 abr. 2015.

BRASIL. Ministério da Educação. Código Matemático Unificado para a Língua Portuguesa. Brasília: Secretaria de Educação Especial, 2006.

CAMARGO, E. P. Inclusão, multissensorialidade, percepção e linguagem. In: CAMARGO, E. P. Inclusão e necessidade educacional especial: compreendendo identidade e diferença por meio do ensino de física e da deficiência visual. São Paulo: Editora Livraria da Física, p. 23-47, $2016 a$.

CAMARGO, E. P. Uma disciplina de formação de professores de Física sob as bases teóricas da multissensorialidade: possibilidades para a inclusão de alunos com deficiência visual. In: CAMARGO, 
E. P. Ensino de ciências e inclusão escolar: investigações sobre o ensino e a aprendizagem de estudantes com deficiência visual e estudantes surdos. Curitiba: CRV, p. 33-53, 2016 b.

CAMARGO, E. P. Saberes docentes para a inclusão do aluno com deficiência visual em aulas de Física. São Paulo: Editora UNESP, 2012.

CAMARGO, E. P. A comunicação como barreira à inclusão de alunos com deficiência visual em aulas de mecânica. Ciênc. educ. (Bauru). Bauru, v. 16, n. 1, p. 259-275, 2010.

CAMARGO, E. P. O ensino de Física no contexto da deficiência visual: elaboração e condução de atividades para alunos cegos e com baixa visão. 2005. 272p. Tese (Doutorado em Educação) Faculdade de Educação, UNICAMP, Campinas, 2005.

CAMARGO, E. P.; NARDI, R. Um estudo sobre a formação do professor de Física no contexto das necessidades educacionais especiais de alunos com deficiência visual. In: Encontro Nacional de Pesquisa em Ensino de Física, X. Londrina, PR, 2006. Atas... CD-Rom, Londrina, Sociedade Brasileira de Física, 2006.

CAMARGO, E. P.; NARDI, R.; VERASZTO, E. V. A comunicação como barreira à inclusão de alunos com deficiência visual em aulas de óptica. Rev. Bras. Ensino Fís., São Paulo ,v. 30, n. 3, p. 3401.1-3401.13,set.,2008.

CAMARGO, E. P.; SCALVI, L. V. A.; BRAGA, T. M. S. Concepções espontâneas de repouso e movimento de uma pessoa deficiente visual total. Cad. Cat. Ens. Fís., v. 17, n. 3: p. 307-327, dez., 2000.

CAMARGO, S.; NARDI, R.; RUBO, E. A. A. Demandas de professores de Física em exercício no Ensino Médio: subsídios para um processo de reestruturação de um curso de licenciatura. Rev. Bras. Pesq. Educ. em Ciênc. v.14, n.3, p.13-40, 2014.

CASSIARI, E. R. Uma reflexão a respeito de potencialidades e fragilidades na implantação do material da Proposta Curricular do estado de São Paulo 2008. 2011. 102 f. Dissertação (Mestrado Profissional em Ensino de Matemática) - Pontifícia Universidade Católica de São Paulo, 2011.

DICKMAN, A. G. et al. Adapting diagrams from physics textbooks: a way to improve the autonomy of blind students. Physics Education, v. 49, n. 5, p. 526-531, 2014.

GASPAR, A. A teoria de Vigotski: um novo e fértil referencial para o ensino de Ciências. 2007, 191p. Tese (Livre Docência) - Faculdade de Engenharia de Guaratinguetá, UNESP, Guaratinguetá, 2007.

LIPPE, E. M. O. Ensino de Ciências e deficiência visual: uma investigação das percepções das professoras de Ciências e da sala de recursos com relação à inclusão. 2010. 109f. Dissertação (Mestrado em Educação para a Ciência) - UNESP, Bauru, 2010.

LIRA, M. C. F.; SCHLINDWEIN, L. M. A pessoa cega e a inclusão: um olhar a partir da psicologia histórico-cultural. Cad. Cedes, v. 28, n. 75, p. 171-190, 2008.

MELO, E. S. Ações colaborativas em contexto escolar: desafios e possibilidades do ensino de Química para alunos com deficiência visual. 2013. 139f. Dissertação (Mestrado em Educação Especial) - UFSCar, São Carlos, 2013.

MICHELS, M. H. O que há de novo na formação de professores para a Educação Especial? Rev. Educ. Espec., v.24, n.40, p.219-232, 2011.

ORLANDI, E. P. Análise de discurso: princípios \& procedimentos. $4^{\mathrm{a}}$ ed. Campinas: Pontes Editores, 2002. 
PÊCHEUX, M. Semântica e discurso: uma crítica à afirmação do óbvio. Tradução: Orlandi et al. Campinas: Unicamp, 1975.

PRESTES, Z. Quando não é quase a mesma coisa: análise de traduções de Lev Semionovitch Vigotski no Brasil - Repercussões no Campo Educacional. 2010, 295 f. Tese (Doutorado em Educação) - Programa de Pós-Graduação em Educação/Faculdade de Educação, Universidade de Brasília, 2010.

SÃO PAULO. Secretaria da Educação. Resolução SE n. 61 de 11 de nov. de 2014. Dispõe sobre a Educação Especial nas unidades escolares da rede estadual de ensino. 2014. Disponível em: http://siau.edunet.sp.gov.br/ItemLise/arquivos/61_14.HTM?Time=09/07/2015\%2013:44:19. Acesso em: 10 abr. 2015.

SÃO PAULO. Secretaria da Educação, Resolução SE n. 8 de 19 de jan. de 2012. Dispõe sobre a carga horária dos docentes da rede estadual de ensino, 2012. Disponível em: http://siau.edunet. sp.gov.br/ItemLise/arquivos/08_12.HTM?Time=26/07/2015\%2018:40:03. Acesso em: 15 jul. 2015.

SÃO PAULO. Governador do Estado de São Paulo. Lei Complementar $\mathbf{N}^{\mathbf{0}} \mathbf{8 3 6}$, de 30 de dezembro de 1997. Institui Plano de Carreira, Vencimentos e Salários para os integrantes do Quadro do Magistério da Secretaria da Educação e dá outras providências correlatas. Diário Oficial do Estado de São Paulo, 1997.

SILVA, M. R.; CAMARGO, E. P. A análise de uma transcrição tinta-braille e suas implicações para o processo de ensino-aprendizagem de Física de alunos usuários do sistema braille. In: Simpósio Nacional de Ensino de Física, XXII. São Carlos, SP, 2017. Anais... . São Carlos, 2017. p. 1-8. Disponível em: http://www1.sbfisica.org.br/eventos/snef/xxii/sys/resumos/T0407-1.pdf. Acesso em: 07 nov. 2017.

SILVA, M. R.; CAMARGO, E. P. Ensino de Física para alunos com deficiência visual: tendências de teses e dissertações no Brasil. In: Congresso Brasileiro de Educação Especial, VII. São Carlos, SP, 2016. Anais... - SP: Galoá, 2016, p. 1-15. Disponível em: https://proceedings.galoa.com.br/cbee7/ trabalhos/ensino-de-fisica-para-alunos-com-deficiencia-visual-tendencias-de-teses-e-dissertacoesno-brasil. Acesso em: 07 nov. 2017.

TATO, A. L. BARBOSA-LIMA, M. C. A. Escrita matemática para alunos usuários do braille: análise do Colégio Pedro II. In: Encontro Nacional de Pesquisa em Educação em Ciências, VII. Florianópolis, SC, 2009. Anais... Florianópolis, 2009, p.1-9. Disponível em: http://posgrad.fae. ufmg.br/posgrad/viienpec/pdfs/1497.pdf. Acesso em: 4 jul. 2015.

TATO, A. L.; BARBOSA-LIMA, M. C. A. Material de equacionamento tátil para portadores de deficiência visual. In: Encontro Nacional de Pesquisa em Educação em Ciências, VI. Florianópolis, SC, 2007. Anais... CD-Rom, Florianópolis, 2007.

VIGOTSKI, L. S. A defectologia e o estudo do desenvolvimento e da educação da criança anormal. Educação e Pesquisa, v.37, n.4, p. 861-870, dez., 2011.

VIGOTSKI, L. S. A construção do pensamento e da linguagem. São Paulo: Martins Fontes, 2001.

VILARONGA, C. A. R.; MENDES, E. G. Ensino colaborativo para o apoio à inclusão escolar: práticas colaborativas entre os professores. Rev. bras. Estud. pedagog., v. 95, n. 239, p. 139-151, 2014.

VYGOTSKI, L. S. Obras Escogidas V: Problemas especiales da defectologia. Madrid: Visor, 1997

VYGOTSKY, L. S. A formação social da mente: o desenvolvimento dos processos psicológicos superiores. 4 ed. São Paulo: Martins Fontes, 1991. 


\section{NOTAS}

${ }^{1}$ Os alunos público-alvo da Educação Especial são aqueles com deficiência, transtornos globais do desenvolvimento e altas habilidades ou superdotação (BRASIL, 2011).

${ }^{2}$ As salas de recursos são ambientes dotados “[...] de equipamentos, mobiliários e materiais didáticos, visando ao desenvolvimento de habilidades gerais e/ou específicas, mediante ações de apoio, complementação ou suplementação pedagógica [...]” (SÃO PAULO, 2014, p. 1).

${ }^{3} \mathrm{O}$ nome deste autor é grafado de diversas maneiras, dadas as distintas traduções de sua obra (PRESTES, 2010). Neste trabalho grafa-se seu nome como "Vigotski". Contudo, ao se referir a citações diretas ou indiretas de outros autores e nas referências bibliográficas, o referido nome foi grafado conforme consta na obra tomada como referência.

${ }^{4}$ Os sinais "[]" “[...]” e “...”, que aparecem nas unidades de análise, referem-se, respectivamente, aos comentários dos autores do artigo, à supressão de trechos da transcrição e à pausa nas falas das entrevistadas.

${ }^{5}$ As unidades de análise sucedidas por S, F e A correspondem, respectivamente, aos recortes dos discursos da professora S, da professora F e da aluna A.

${ }^{6}$ As ATPC - Aulas de Trabalho Pedagógico Coletivo - fazem parte da jornada docente na rede estadual de ensino de São Paulo (SÃO PAULO, 2012) e devem ser utilizadas para reuniões e outras atividades pedagógicas e de estudo, de caráter coletivo, organizadas pelo estabelecimento de ensino, bem como para atendimento aos pais de alunos (SÃO PAULO, 1997).

${ }^{7} \mathrm{O}$ "Caderno do Aluno" juntamente com o "Caderno do Professor" foram implementados na Rede Estadual de São Paulo em 2008 e contemplam a Proposta Curricular do Estado de São Paulo, que propõe um currículo para o Ensino Fundamental II e Ensino Médio (CASSIARI, 2011).

Submetido em 30/03/2017

Aprovado em 17/11/2017

\section{Contato:}

Marcela Ribeiro da Silva

Programa de Pós-Graduação em Educação para a Ciência

Faculdade de Ciências - UNESP - Bauru

Av. Eng. Luiz Edmundo Carrijo Coube, 14-0 - Bairro Vargem Limpa.

CEP: 17.033-360 - Bauru, SP - Brasil 


\section{APÊNDICE A - ROTEIROS SEMIESTRUTURADOS DAS ENTREVISTAS}

\section{Roteiro semiestruturado da entrevista com a professora de Física}

1. Dados pessoais: idade, formação inicial e formação continuada, tempo em que atua na escola (e se atua em outras escolas), tempo em que atua na função desempenhada, etc.

2. O que você entende por inclusão?

3. O que você entende por deficiência visual?

4. O que você sabe sobre a história visual da aluna (se a deficiência visual é congênita ou adquirida; se é adquirida, a partir de que idade)?

5. Como é sua relação com a aluna com deficiência visual? E como é a interação desta aluna com os colegas de classe?

6. Sobre o aluno com deficiência visual nas aulas de Física: Já deu aula para outros alunos com deficiência visual? Como é trabalhar com o aluno com deficiência visual em sala de aula? Quais são as dificuldades e desafios que encontra para ensinar Física a este aluno? Utiliza alguma estratégia para que tal aluna participe de suas aulas (quais estratégias)? Quais as principais dificuldades que você imagina que a aluna tenha durante as aulas de Física? A escola fornece algum material didático adaptado para esta aluna?

7. Como a aluna tem sido avaliada na sua disciplina?

8. Você conhece ou sabe dizer o que é a sala de recursos? Sabe que tipo de trabalho é desenvolvido lá?

9. Sobre parcerias que este profissional possa estabelecer com o da Educação Especial: Há parcerias? Como são realizadas? Há alguma circunstância em que você busca articular-se com o professor da sala de recursos? Em caso afirmativo: que dificuldades você encontra ao buscar a colaboração do professor da Educação Especial? Quais resultados você observa desta parceria? Como você vê a sua interação com o professor da sala de recursos? O que poderia melhorar?

10. Ao longo de minhas observações na escola, notei que existe um trabalho feito pelo professor da sala de recursos de transcrição de provas/trabalhos da aluna. Como se estabeleceu tal dinâmica de envio e recebimento dos materiais (a serem) transcritos? Quais as dificuldades que você encontra no estabelecimento desta dinâmica? 
11. Conhecimentos que o professor possa ter tido com conteúdos referentes à Educação Especial (quer seja em sua formação inicial, quer seja como curso de formação continuada). Caso afirmativo, de que forma tais conhecimentos contribuem para a sua prática docente?

\section{Roteiro semiestruturado da entrevista com a professora da sala de recursos}

1. Dados pessoais: idade, formação inicial e formação continuada, tempo em que atua na escola (e se atua em outras escolas), tempo em que atua na função desempenhada, etc.

2. O que você entende por inclusão?

3. Sobre a sala de recursos: Qual a função da sala de recursos no processo de ensino e aprendizagem de alunos com deficiência visual? Quais materiais/equipamentos/ recursos existem na sala de recursos (quais deles se destinam especificamente aos alunos com deficiência visual)?

4. Qual o trabalho do docente da sala de recursos?

5. Quantos alunos são atendidos na sala de recursos e com que frequência?

6. Sobre a aluna com deficiência visual: Como é trabalhar com esta aluna? Quais dificuldades e desafios você encontra? Como é a sua relação com a aluna com deficiência visual?

7. O que você sabe sobre a história visual da aluna (se a deficiência visual é congênita ou adquirida; se é adquirida, a partir de que idade)?

8. Existe alguma parceria com o professor de Física? Este profissional solicita e ou já solicitou suas orientações e apoio para adaptar algum material didático? Com que frequência? Como ocorre a adaptação do material didático (quais são os materiais ou recursos geralmente empregados na adaptação)? Quais dificuldades você tem ou já teve ao atender as solicitações feitas pelo professor de Física?

9. Como você vê a sua interação com o docente de Física? O que poderia melhorar?

10. Você encontra dificuldades na transcrição das provas/trabalhos/conteúdos de Física? Como se estabelece essa dinâmica de transcrever tais materiais? Como se estabelece o contato com o professor da sala regular para envio e recebimento de materiais (a serem) transcritos?

11. Além das transcrições, de alguma forma a aluna solicita seu apoio com relação à disciplina de Física? 


\section{Roteiro semiestruturado da entrevista com a aluna cega}

1. Dados pessoais: idade, escolaridade, tempo em que estuda na escola, se já estudou em outras escolas, etc.

2. Sobre a história visual da aluna: se é cega ou tem baixa visão; se a deficiência visual é congênita ou adquirida; se é adquirida, a partir de que idade.

3. Sobre as aulas de Física: se gosta da disciplina (o que gosta ou o que chama a atenção; o que não gosta, e; os motivos que a levam a gostar ou não dos aspectos levantados).

4. Como tem sido as aulas de Física; se participa das aulas de Física; quais as principais dificuldades; se o professor utiliza algum material adaptado; o que poderia melhorar nas aulas dessa disciplina.

5. Como tem sido seu desempenho na disciplina?

6. Sobre a interação com o professor de Física e com os colegas.

7. Sobre a sala de recursos: quais atividades desenvolve neste ambiente; como essas atividades são desenvolvidas; como é a relação desta aluna com o professor da sala de recursos.

8. As atividades desenvolvidas na sala de recursos contribuem para a sua aprendizagem em Física? De que forma?

ERRATA

Doi da errata: 10.1590/1983-211720182001016

Doi do original: 10.1590/1983-21172018200102

Para o artigo:

RIBEIRO DA SILVA, MARCELA; DE CAMARGO, EDER PIRES. O Atendimento Pedagógico Especializado E O Ensino De Física: Uma Investigação Acerca Do Processo De Ensino E Aprendizagem De Uma Aluna Cega. Ens. Pesqui. Educ. Ciênc. (Belo Horizonte), Belo Horizonte, v. 20, e2894, 2018, DOI: 10.1590/1983-21172018200102.

Em autores do artigo,

Onde se lê

RIBEIRO DA SILVA, MARCELA

Leia-se

SILVA, MARCELA RIBEIRO DA

Onde se lê:

DE CAMARGO, EDER PIRES

Leia-se

CAMARGO, EDER PIRES DE 